\title{
External Dacryocystorhinostomy versus Canalicular Silicone Intubation with Mitomycin C in Primary Acquired Nasolacrimal Duct Obstruction
}

\author{
Amin Faisal Ellakwa ( $\sim$ ellakwa@yahoo.com ) \\ Menoufia University https://orcid.org/0000-0002-6661-2224 \\ Osama Abdallah Elmorsy \\ Menoufia University \\ Marwa Ali Zaki \\ Menoufia University
}

\section{Research Article}

Keywords: External DCR, canalicular silicone intubation, Mitomycin C

Posted Date: December 28th, 2018

DOI: https://doi.org/10.21203/rs.2.154/v1

License: (c) (i) This work is licensed under a Creative Commons Attribution 4.0 International License.

Read Full License 


\section{Abstract}

Purpose: To compare external dacryocystorhinostomy versus canalicular silicone intubation with the use of Mitomycin C (MMC) in primary acquired nasolacrimal duct obstruction (NLDO).

Methods: the study was carried out at the department of Ophthalmology, Menoufia university Hospital, Egypt, between June 2012 to July 2014. Fifty-six patients who were diagnosed with primary acquired NLDO. Patients were randomly allocated into two groups: thirty cases underwent external DCR and twenty-six cases underwent silicone intubation with MMC.

Results: No significant difference was detected in success and failure rates between external DCR (90\%) and silicon intubation with MMC (80.7\%) at 6 months follow up. Also, both procedures were associated with low rate of intraoperative adverse events, with no postoperative adverse events were detected, however, intubation was relatively safer than DCR.

Conclusion: Silicon intubation with MMC is as effective and safe as external DCR and should be considered as a minimally invasive procedure in primary acquired NLDO.

Keywords: External DCR, canalicular silicone intubation, Mitomycin C.

\section{Background}

Nasolacrimal duct obstruction (NLDO), congenital or acquired, is a highly prevalent condition that usually presents with persistent epiphora and/or discharge. The acquired variety presents more commonly in fifth to seventh decade of life, affecting women three times more than men. ${ }^{1}$ Chronic tear stasis and secondary infection frequently lead to acute exacerbations of dacryocystitis, mucocele, chronic conjunctivitis, corneal ulcer, orbital cellulitis in untreated cases and pan-ophthalmitis in cases having undergone intraocular surgeries. ${ }^{2}$ External Dacryocystorhinostomy (DCR) is the gold standard procedure for NLDO that is considered as the major indication for DCR. ${ }^{3-5}$

Since first introduced by Addeo Toti, different modifications have been applied for the external DCR procedure. Its Success rate ranges from 80 to $90 \%$ according to different patient's and surgeon's factors. ${ }^{3,5-9}$ Nonetheless, and given its invasive and lengthy nature, external DCR has its own drawbacks. Intraoperative complications, such as extensive bleeding, aren't infrequent. Moreover, failure rate of external DCR is estimated to be $10 \%$. It is attributed to different factors, however, closure of osteotomy and common canalicular obstruction are the two major causes of failure. Both of them can be attributed, in part at least, to fibrous tissue growth and synechia. ${ }^{1,4,7}$

In contrast, canalicular intubation is a less-invasive procedure that has lower success rates to external DCR, ranging from $60-80 \%$, so it is usually reserved for mild to moderate uncomplicated cases. Considering its relative safety, modified techniques of intubation that can enhance the success rate should be considered ${ }^{10-14}$. Mitomycin C (MMC) is antiproliferative agent that suppresses fibrous tissue 
growth through inhibition of DNA and protein synthesis. It has been integrated in many ocular surgeries, with outstanding benefits, to inhibit scarring. Lacrimal surgery wasn't away from this where MMC has been investigated with DCR that yielded higher success rates. MMC has been tried with intubation as well, however, limited evidence exists for this procedure. ${ }^{8,9,15-19}$

In this study, we hypothesize that intraoperative application of MMC with silicon intubation isn't inferior to external DCR. Given the safety and ease of the intubation procedure, intubation with MMC could be an alternative for DCR in primary acquired NLDO.

\section{Methods}

All patients with chief symptoms of watery eye and discharge in Menoufia university hospitals were evaluated and only patients with primary acquired NLDO were considered. All other secondary causes of NLDO were excluded, including but not limited to, chronic granulomatous inflammation, chronic dacryocystitis, atrophic sac, lacrimal sac malignancy, nasal causes as deviated nasal septum, nasal polyps or atrophic rhinitis and traumatic bony deformity in the nasal region. In addition, patients with entropion, ectropion, lid laxity, canalicular and common canalicular obstruction were excluded from the study.

From June 2012 to July 2014, fifty-six patients who with primary acquired NLDO were eligible for the study. They were counselled for enrollment in the study. Enrolled patients signed a well-informed consent and were randomly allocated into two groups: group A (30 cases) for external DCR and group B (26 cases) for silicone intubation with MMC. All study procedures were carried out in accordance with declaration of Helsinki and were approved by the institutional ethical committee.

\section{Patients' Evaluation}

Enrolled patients were thoroughly examined with particular reference to the lacrimal apparatus. Nasal examination was accomplished by ENT specialist, essentially to rule out significant deviation of nasal septum of hypertrophied turbinate or nasal polyps. Preoperatively, anatomical and physiological patency of the lacrimal drainage system was evaluated with lacrimal syringing and dye disappearance test respectively.

\section{Surgical Techniques}

group a

Thirty patients underwent external DCR under general anesthesia with standard sterilization procedures. Ipsilateral nasal cavity was packed by roller gauze soaked in adrenaline 1:200,000. Five milliliters of 
adrenaline 1:200,000 were infiltrated around lacrimal sac for hemostasis. A curvilinear incision of 10-15 $\mathrm{mm}$ length was made along the anterior lacrimal crest starting $3 \mathrm{~mm}$ above the medial palpebral ligament and $3 \mathrm{~mm}$ medial to medial canthus.

The orbicularis oculi muscle fibers were separated with artery forceps and with blunt dissector. Cat's paw retractors were used to retract the edges of incision. With the help of Traquair's periosteal elevator, the periosteum overlying and medial to the anterior lacrimal crest was exposed and elevated. The sac was separated from the lacrimal fossa with a blunt dissector

The smaller end of the blunt dissector was used to fracture Lamina papyracea, the parchment like bone of the posterior half of the lacrimal fossa. the nasal mucosa was stripped from lacrimal bone with the help of Traquair's periosteal elevator, to avoid damage to the nasal mucosa. An osteotomy of approximately $12.5 \times 10 \mathrm{~mm}$ was created with successive punching of bone by Cittelli's punch. Oozing of blood was controlled by packing with ribbon gauze and suction.

The upper punctum was dilated with Nettleship's punctum dilator, the position of the common canaliculus and related part of the medial sac wall is confirmed by Bowman's probe which was passed through the upper canaliculus to confirm the position. Lacrimal sac and nasal mucosa were opened in a ' $\mathrm{H}$ ' fashion with the no.11 Bard-Parker blade and Bowman's probe was in place, to form a large anterior and smaller posterior flap. The Bowman's probe was removed. Posterior flaps sutured and then anterior flaps.

The orbicularis muscle was closed using 6-0 vicryl with interrupted sutures. The skin incision was closed by with running subcuticular suture using 6-0 vicryl. Antibiotic ointment was instilled into the eye, the wound dressing with betadine-soaked gauze and a pressure bandage applied.

\section{group B}

Twenty-six patients underwent canalicular silicone intubation with MMC under general anesthesia. Cotton soaked in adrenaline 1:200,000 was packed in the nose. The inferior and superior puncta were dilated, then Bowman's probe was gently inserted into the inferior canalicular system, until a hard stop was felt in the lacrimal sac, after which it was rotated into the NLD to reach below the inferior concha. The probe was then withdrawn via the inferior punctum and the process was repeated for the upper canaliculus.

After irrigation with normal saline to confirm duct patency, irrigation was performed by introducing $1 \mathrm{ml}$ of $\mathrm{MMC}(0.5 \mathrm{mg} / \mathrm{ml})$ into the duct with a syringe, the ocular surface then irrigated with $10 \mathrm{ml}$ of normal saline. Cotton tipped applicator was placed in the nasal cavity before irrigation to absorb excess fluid to minimize systemic absorption. Intubation was done by a silicone tube connected by each of its end to a malleable steel guide. A grooved director was placed under the inferior turbinate to guide the probe out of the nose, after which the steel guide was cut from the silicone tube. The procedure was then repeated 
through the other punctum. The two silicone tubes were tied together with polypropylene 6.0 suture and fixed to the lateral wall of the nose.

\section{Postoperative management}

DCR patients were given systemic antibiotics and analgesics for 5 days. Topical antibiotics were instilled 5 times daily for 7 days. The nasal pack was removed after 24 hours, the first dressing was done at $24 \mathrm{hrs}$. Incision area inspected for any gaping, wound infection or discharge. Sutures were removed at 1 week postoperative. For Intubation patients, topical steroids and antibiotics were applied 5 times daily for 2 weeks. The silicone tubes remained in situ for 3 months, then were removed.

Follow up visits were arranged at 1 week, 1 month, 3 months and 6 months after the surgery. Patients were evaluated subjectively (watering and discharge) upon which were classified as asymptomatic (no watering, no discharge), improvement or no improvement. Objectively, patency of lacrimal passage was tested by height of tear meniscus and lacrimal syringing. On the basis of subjective and objective evaluation, patients were categorized into three groups: successful surgery (asymptomatic, normal tear meniscus and patent lacrimal system with syringing procedure), improvement (watery eye and/or discharge, moderate tear meniscus and partially patent lacrimal system with syringing procedure with mild regurgitation from the puncta) and failed surgery (watery eye and/or discharge, high tear meniscus and non-patent lacrimal system).

Statistical analysis was performed with IBM SPSS for Windows (Version 22.0, Armonk, NY: IBM Corp). Categorical data was expressed as numbers and percentage, while numerical variables were expressed as mean \pm SD. Normality of data variables were checked. For normally distributed data, student t-test was used to compare the means between both study groups. Chi-square test was used to compare the categorical variables between both groups.

\section{Results}

Fifty-six eyes of 56 patients were enrolled in our study, including 13 males and 43 females. Demographic characteristics of the patients are outlined in tables $1 \& 2$. No significant difference was detected between both groups in gender $(p=0.8)$ or age $(p=0.9)$.

Regarding safety, intra- and postoperative complications were documented for both groups. In group A, extensive hemorrhage was encountered in $5(16.6 \%)$ patients and nasal bleeding in $3(10 \%)$ patients, for whom nasal packing was performed. In group $B$, mild hemorrhage from punctum during intubation was encountered in $2(7.7 \%)$ patients and mild to moderate nasal hemorrhage in $1(3.8 \%)$ patient that was controlled without nasal packing. No significant difference was detected between both groups, regarding the overall rate of complications $(p=0.3)$.

At 1-week, successful surgery was obtained in 47 patients: 27 (90\%) and $20(76.9 \%)$ patients in groups A and $B$ respectively, with no significant difference between both groups $(p=0.4)$. Similarly, no significant 
difference was detected between failure and improvement proportions in both groups. Table 3 plots the 1week outcomes for both groups.

At 3 months, success was maintained in 27 (90\%) and 20 (76.9\%) patients in group A and B respectively. However, in group B, one case that was labelled as failure at 1-week showed improvement at 3 months. Nonetheless, no significant difference was found between both groups $(p=0.3)$. Table 4 outlines the 3months results.

At 6 months, success rate was similar to that at 1 week and 3 months for group A. for group B, success rate showed slight increment (21 patients, $80.7 \%$ ). However, no statistically significant difference was detected between both groups. Table 5 outlines the 6-months results.

Subsequent procedures were performed for non-successful surgeries, those that were labelled as failed or improvement. In group A, 3 patients underwent a second DCR. Osteotomy site was examined by anterior rhinoscopy by ENT specialist that revealed adhesions at the osteotomy site. DCR was repeated with use of MMC at the osteotomy site and reported improvement on follow-up. In group B, DCR was performed in 1 case. In the cases where the tube fell out early (2 cases) or had to be removed early due to a slit inferior punctum ( 2 cases), the 4 cases reported improvement on follow up.

\section{Discussion}

Acquired NLDO is a common bothering condition, that usually requires surgical intervention. External DCR is the gold standard technique with relatively high success rates of $80-90 \% .2,3,20$ Nonetheless, its technical challenge and invasive nature as long as intra and postoperative adverse events raised the need to a safer, yet similarly effective, procedure. Silicon intubation is an easy and minimally invasive procedure that possesses comparable effectiveness in mild to moderate cases. ${ }^{10,11,14,16}$ In contrast, severe and complicated cases aren't good candidates for intubation. ${ }^{12}$

MMC, an antiproliferative agent, has been established as an adjunctive in many ocular surgeries including, but not limited to, trabeculectomy, pterygium and photorefractive keratectomy. Inhibiting collagen production through suppressing DNA and protein synthesis, MMC can brake fibrous tissue growth, a process that is usually encountered with failed surgeries. ${ }^{3,21-23}$ In DCR and SI, MMC was supposed to enhance the success rate, hence investigated for both procedures. $4,8,9,15,17,19$

For DCR, Kao et al compared conventional external DCR versus that with MMC. A $100 \%$ success rate was reported for MMC group compared to $87.5 \%$ for the conventional technique. Kao et al elaborated the cause of that discrepancy to be the adhesion formation on the osteotomy. In the MMC group, no adhesions were detected, while in the control group, $25 \%$ of patients had adhesions between the ostium and the nasal septum. After failed DCR, a second DCR is usually performed where measures are taken to get over the expected failure. ${ }^{24}$ Similarly, Qidwai reported comparable success rates for DCR with MMC. ${ }^{8}$ 
In a case series, Yeatts and Neves reported anatomical and physiological patency as well as subjective improvement in eight cases who underwent a second DCR. ${ }^{25}$

SI with MMC was investigated as a potential alternative for DCR in few studies. In 2007, Tabatabaie et al reported their RCT, comparing SI + MMC versus SI alone for patients with NLDO for 8 months of follow up. Overall success rate of SI was $63.7 \%$ and $23 \%$ in simple epiphora and chronic dacryocystitis respectively. MMC application enhanced the success rate of SI for patients with more than 6 months duration of symptoms ( $71.4 \%$ success rate with MMC versus $29.4 \%$ without MMC, $p=0.02$ ). For patients with symptoms less than 6 months duration, no significant difference was detected between both groups. $^{26}$

In our study, we aimed at exploring if SI can be an alternative for the lengthy and invasive DCR. We hypothesized that MMC application with SI could push up the success rate to match that of external DCR. To test this hypothesis, 56 patients with primary acquired NLDO were randomly allocated into 2 groups: external DCR and SI with MMC. Patients were followed up for 6 months regarding symptomatic and objective improvement. At 6 months, external DCR and SI with MMC had success rates of $90 \%$ and 80.7 $\%$ respectively with no statistically significant difference between both groups.

Regarding success rates, it was comparable with those reported for external DCR (85-99\%), but higher than those for SI alone without MMC. Fulcher et al. achieved $22 \%$ complete success $(n=12)$ after 2 years of follow up for NLDO ${ }^{27}$, whereas Pashby et al. reported a success rate of $60 \%(n=5)$ after a follow up period of 9 months. ${ }^{13}$ Similarly, Kashkouli et al. reported $59 \%$ complete success rate with $(n=22)$ after a mean follow up period of 15 months for SI in adults with partial NLDO. ${ }^{28}$ Moreover, our success rate was higher than that reported for SI with MMC by Tabatabaie et al. (80.7\% versus $71.4 \%$ ). This can be attributed to the inclusion criteria in both studies. Tabatabaie et al. considered SI with MMC for all patients with NLDO including those with chronic dacryocystitis. In our study, those patients were excluded given the established fact of the low success rate of SI for those patients. ${ }^{26}$

Sharing comparable success rates, external DCR and SI with MMC come face to face again in terms of safety. In our study, SI with MMC was relatively safe procedure in terms of intra- and postoperative complications. While $5(16.7 \%)$ cases of DCR experienced extensive bleeding intraoperatively, no similar events were encountered with SI. In addition, postoperative nasal bleeding was reported in one (3.8\%) patient with SI, while 3 (10\%) patients in DCR group had this event. In terms of safety, although statistically insignificant, our results go hand by hand with literature where it is evident that $\mathrm{SI}$ is superior in terms of duration of surgery and anesthesia, adverse events and technical difficulty, in addition to maintaining the normal anatomical pathway for lacrimal drainage. Statistical insignificance may be attributed to the relatively low sample size.

To extend the safety issue, it is to be noted that SI has its own complications. such as tube breakage, tube displacement, and retained tube after severance of the canthal loop, infection, and corneal abrasion. 
Moreover, removal of the tube may be problematic without using a nasal endoscope in some cases. In this study, there were 4 slit inferior puncta, and 2 premature extrusions of the tube.

In this study, patients were followed up for 6 months only, a relatively short duration that could overestimate the success of SI. Longer follow up duration can reveal long-term stability of the obtained outcomes for both procedures.

\section{Conclusion}

While external DCR is the gold standard procedure for primary NLDO as well as complicated cases, SI with MMC could achieve comparable success rates in primary acquired NLDO, hence should be considered as an alternative as a safe and minimally invasive procedure.

\section{Abbreviations}

NLDO: Nasolacrimal duct obstruction

DCR: Dacryocystorhinostomy

MMC: Mitomycin C

\section{Declarations}

Ethics approval and consent to participate: The study methods adhered to the tenets of the Declaration of Helsinki for use of human participants in biomedical research and were approved by ethical committee of Menoufia medical college.

Consent for publication: Not applicable

Availability of data and material: available on need by corresponding author

\section{Authors' contributions:}

AF analyzed and interpreted the patient data with primary acquired NLDO.

OE performed the surgical procedures and postoperative data,

MZ was a major contributor in writing the manuscript. All authors read and approved the final manuscript

Competing interests: No

Funding: No

Acknowledgements: Not applicable 
Clinical Trials.gov ID: NCT03780868

\section{References}

1. Shun-Shin GA, Thurairajan G. External dacryocystorhinostomy--an end of an era? Br J Ophthalmol. 1997;81(9):716-717.

2. Duke-Elder S, MacFaul PA. Diseases of the lacrimal passages. Syst Ophthalmol. 1974;13(Part II):675724.

3. Picó G. A modified technique of external dacryocystorhinostomy. Am J Ophthalmol. 1971;72(4):679690.

4. Qian Z, Zhang Y, Fan X. Clinical Outcomes of Dacryocystorhinostomy With or Without Intraoperative Use of Mitomycin C: A Systematic Review and Meta-Analysis. J Ocul Pharmacol Ther. 2014;30(8):615-624.

5. Rosen N, Sharir M, Moverman DC, Rosner M. Dacryocystorhinostomy with silicone tubes: evaluation of 253 cases. Ophthalmic Surg. 1989;20(2):115-119.

6. Shams PN, Chen PG, Wormald PJ, et al. Management of Functional Epiphora in Patients With an Anatomically Patent Dacryocystorhinostomy. JAMA Ophthalmol. 2014;132(9):1127.

7. Allen K, Berlin AJ. Dacryocystorhinostomy failure: association with nasolacrimal silicone intubation. Ophthalmic Surg. 1989;20(7):486-489.

8. Qidwai N, Jafri Raza H. Comparison of Dacryocystorhinostomy with Mitomycin C Against Dacryocysto- rhinostomy with Intubation. Pakistan J Ophthalmol. 2012;28(4):214-218.

9. Ari Ş, Gun R, Surmeli S, Atay AE, Çaca Î. Use of adjunctive mitomycin C in external dacryocystorhinostomy surgery compared with surgery alone in patients with nasolacrimal duct obstruction: A prospective, double-masked, randomized, controlled trial. Curr Ther Res. 2009;70(4):267-273.

10. Soll DB. Silicone intubation: an alternative to dacryocystorhinostomy. Ophthalmology. 1978;85(12):1259-1266.

11. Psilas K, Eftaxias V, Kastanioudakis J, Kalogeropoulos C. Silicone intubation as an alternative to dacryocystorhinostomy for nasolacrimal drainage obstruction in adults. Eur J Ophthalmol. 1993;3(2):71-76.

12. Lauring L. Silicone intubation of the lacrimal system: pitfalls, problems and complications. Ann Ophthalmol. 1976;8(4):489-498.

13. Pashby RC, Rathbun JE. Silicone tube intubation of the lacrimal drainage system. Arch Ophthalmol (Chicago, III 1960). 1979;97(7):1318-1322.

14. Angrist RC, Dortzbach RK. Silicone intubation for partial and total nasolacrimal duct obstruction in adults. Ophthal Plast Reconstr Surg. 1985;1(1):51-54.

15. Liu D, Bosley TM. Silicone nasolacrimal intubation with mitomycin-C: a prospective, randomized, double-masked study. Ophthalmology. 2003;110(2):306-310. 
16. Sinha MK, Bajaj MS, Pushker N, Ghose S, Chandra M. Efficacy of Probing with Mitomycin-C in Adults with Primary Acquired Nasolacrimal Duct Obstruction. J Ocul Pharmacol Ther. 2013;29(3):353-355.

17. Liao SL, Kao SC, Tseng JH, Chen MS, Hou PK. Results of intraoperative mitomycin C application in dacryocystorhinostomy. Br J Ophthalmol. 2000;84(8):903-906.

18. Hossam Z. Closed Intubation with Mitomycin C Application for Nasolacrimal Duct Obstruction Patients beyond the Age of Two Years. Open Access J Ophthalmol. 2018.

19. Heirati SZMD, Rajabi AMD, Kasaee MTMD, AbolfazI MD. Silicone Intubation With Intraoperative Mitomycin C for Nasolacrimal Duct Obstruction in Adults: A Prospective, Randomized, Double masked Study. Iran J Ophthalmol. 2016;19(4):7-12.

20. Linberg J V., McCormick SA. Primary Acquired Nasolacrimal Duct Obstruction. Ophthalmology. 1986;93(8):1055-1063.

21. Mearza AA, Aslanides IM. Uses and complications of mitomycin C in ophthalmology. Expert Opin Drug Saf. 2007;6(1):27-32.

22. Martins TG dos S, Costa ALF de A, Alves MR, Chammas R, Schor P. Mitomycin C in pterygium treatment. Int J Ophthalmol. March 2016.

23. Wilkins M, Indar A, Wormald R. Intraoperative Mitomycin C for glaucoma surgery. Cochrane Database Syst Rev. October 2005.

24. Kao SC, Liao CL, Tseng JH, Chen MS, Hou PK. Dacryocystorhinostomy with intraoperative mitomycin C. Ophthalmology. 1997;104(1):86-91.

25. Yeatts RP, Neves RB. Use of mitomycin C in repeat dacryocystorhinostomy. Ophthal Plast Reconstr Surg. 1999;15(1):19-22.

26. Tabatabaie SZ, Heirati A, Rajabi MT, Kasaee A. Silicone intubation with intraoperative mitomycin C for nasolacrimal duct obstruction in adults: a prospective, randomized, double-masked study. Ophthal Plast Reconstr Surg. 23(6):455-458.

27. Fulcher T, O’Connor M, Moriarty P. Nasolacrimal intubation in adults. Br J Ophthalmol. 1998;82(9):1039-1041.

28. Kashkouli MB, Parvaresh MM, Modarreszadeh M, Hashemi M, Beigi B. Factors affecting the success of external dacryocystorhinostomy. Orbit. 2003;22(4):247-255.

\section{Tables}




\begin{tabular}{|c|c|c|c|c|c|c|}
\hline Age in years & \multicolumn{2}{|c|}{ Group A } & \multicolumn{2}{c|}{ Group B } & \multicolumn{2}{c|}{ Total } \\
\cline { 2 - 7 } & No. & $\%$ & No. & $\%$ & No. & $\%$ \\
\hline $21-30$ & 14 & 46.6 & 10 & 38.46 & 24 & 42.8 \\
\hline $31-40$ & 10 & 33.3 & 10 & 38.46 & 20 & 35.7 \\
\hline $41-50$ & 3 & 10 & 4 & 15.3 & 7 & 12.5 \\
\hline $51-60$ & 3 & 10 & 2 & 7.6 & 5 & 8.9 \\
\hline
\end{tabular}

\begin{tabular}{|c|c|c|c|c|c|c|c|}
\hline \multirow[t]{2}{*}{ Gender } & \multicolumn{2}{|c|}{ Group A } & \multicolumn{2}{|c|}{ Group B } & \multicolumn{2}{|c|}{ Total } & $P$ value \\
\hline & No. & $\%$ & No. & $\%$ & No. & $\%$ & \multirow[t]{3}{*}{0.98} \\
\hline Male & 7 & 23.3 & 6 & 23.1 & 13 & 23.2 & \\
\hline Female & 23 & 76.6 & 20 & 76.9 & 43 & 76.8 & \\
\hline \multicolumn{7}{|c|}{ Table 2: Gender distribution } & \\
\hline
\end{tabular}

\begin{tabular}{|c|c|c|c|c|c|c|c|}
\hline Symptoms, Tear meniscus & \multicolumn{3}{|c|}{ Group A } & \multicolumn{3}{|c|}{ Group B } & \multicolumn{2}{|c|}{ Total } & P value \\
\cline { 2 - 7 } height \& Patency & No. & \% & No. & \% & No. & \% & \multirow{0}{*}{$\mathbf{4 . 4 2}$} \\
\hline Successful & 27 & 90 & 20 & 76.9 & 47 & 83.9 & \\
\hline Improvement & 2 & 6.7 & 4 & 15.3 & 6 & 10.7 \\
\hline No Improvement & 1 & 3.3 & 2 & 7.7 & 3 & 5.4 & \\
\hline Table 3: Post-operative condition at 1 week & \\
\hline
\end{tabular}

\begin{tabular}{|c|c|c|c|c|c|c|c|}
\hline $\begin{array}{c}\text { Symptoms, Tear meniscus } \\
\text { height \& Patency }\end{array}$ & \multicolumn{2}{|c|}{ Group A } & \multicolumn{2}{|c|}{ Group B } & \multicolumn{2}{|c|}{ Total } & P value \\
\cline { 2 - 7 } & No. & $\%$ & No. & $\%$ & No. & \% & \multirow{2}{*}{$\mathbf{0 . 3 5}$} \\
\hline Successful & 27 & 90 & 20 & 76.9 & 54 & 83.9 & \\
\hline Improvement & 2 & 6.7 & 5 & 19.2 & 4 & 7.1 & \\
\hline No Improvement & 1 & 3.3 & 1 & 3.8 & 2 & 5.4 & \\
\hline \multicolumn{6}{|c|}{ Table 4: Post-operative condition at 3 months } & \\
\hline
\end{tabular}

